\title{
COMPUTATION OF HEAT AND MASS DISTRIBUTION IN SINTER LAYER BASED ON PDES
}

\author{
Kyrylo S. Krasnikov \\ Systems Software Department \\ Dniprovsky State Technical University, \\ Dniprobudivs'ka St, 2, Kamianske, Ukraine, 51918, kir_kras@ukr.net
}

Paper history:

Received 2 April 2018

Received in revised form 12 October 2018

Accepted 23 November 2018

Available online 31 December 2018

Keywords:

Ore sintering model,

thermodynamics,

mass transfer,

system of partial differential equations.

\begin{abstract}
The article presents mathematical model of interconnected physical processes on sintering machine during agglomeration of iron ore pellets. The mathematical model uses a system of partial differential equations. Velocity of the horizontal movement of the layer and the vertical velocity of the air movement through the layer as well as phase transition and simple chemical reactions of pellet and air components are taken into account in this model. The purpose of simulation is to determine the time dependency of sinter temperature distributed along the length and height of the layer and then define rational parameters for optimization of metallurgical process. In addition, concentration of sinter and gas components distributed along the height of the layer is computed. The numerical experiment shows that temperature front, which is lower in the layer cross-section, is sharper in comparison with the upper front, where the obtained agglomerate is cooled, as water requires a considerable amount of energy to evaporate. The obtained results are qualitatively consistent with the data in scientific literature.
\end{abstract}

Copyright $\mathbb{C}$ Research Institute for Intelligent Computer Systems, 2018. All rights reserved.

\section{INTRODUCTION}

Nowadays, more than a half of steel industry uses sinter as a raw for loading into the blast furnace. Lengthy agglomeration machine, which is used for sinter production, firstly heats the layer of pellets using gas-burners and then cools the obtained agglomerate. From the practical point of view the scientists are interested in mathematical modeling of this process to determine the state of the sinter inside the layer at different points of time and to search for the rational parameters of the process in order to save resources.

The authors of the work [1] presented a mathematical model of agglomeration process, which is described by a system of differential equations including coke's average diameter decreasing and sinter temperature changing; drawings with visualization of calculation results; operation parameters of the agglomachine, which can be used in testing of a mathematical model. Some of the multipliers in the equations do not depend on temperature and the values for the heat in the expressions are not properly described, so such a model needs improvement.

In paper [2] the authors performed a detailed analysis of the computational results based on the mathematical model developed in [1] with temperature plots, the amount of melt, concentration of $\mathrm{FeO}$ and gases $(\mathrm{O} 2$ and $\mathrm{CO} 2)$ along the length and height of the sinter layer. A number of recommendations are given to increase the specific productivity of sinter plants.

In work [3], a detailed review of the mathematical models of sintering is made. The authors emphasize the necessity of improving the analyzed models taking into account such important parameters as the layer height, the moisture of the sinter, its granulometric composition, carbon concentration, etc., which will allow technologists to consider a wider range of situations encountered in practice.

The authors of [4] offer a detailed description of the sintering process on the agglomeration machine, starting with the ignition stage, paying attention to temperature, moisture concentration in the layer, 
rarefaction in vacuum chambers and the sinter cooling.

At the conference ITMM-2017 [5] it was reported on the existing mathematical models of agglomeration and the emphasis was laid on the need to take into account the speed of air movement with oxygen and water vapor through the sinter layer while constructing the mathematical model.

The authors of the works $[6,7]$ considers convection and diffusion of chemical substances, momentum, and energy in three dimensions taking into account phase transitions in partial differential equations. They are solved for steady state. Also, unsteady solution is needed to fully understand the sinter layer changes in time.

Agglomeration process includes air movement through the sinter layer with the speed, which depends on the sinter permeability. In work [8], the author analyzes this permeability in case of sinter components melting taking into account the basicity. The author of the work [9] proposes onedimensional unsteady mathematical model of mass and heat transport in fixed sinter layer considering evaporation and condensation of moisture.

Article [10] is devoted to mathematical description of heat transfer coefficient taking into account a set of chemical reactions of the sintering process.

The authors of the works $[11,12]$ predict the temperature inside the sinter layer in dependence on time and coke combustion rate. Also details of coke combustion are presented in [13] considering homogeneous, heterogeneous reactions and heat transfer between solid and gas phases.

In thesis [14] among other things the author emphasizes the importance of the required temperature level for sintering process: low temperature is not sufficient; very high temperature causes excessive melting of layer and decreases its permeability.

The author of the works $[15,16]$ models heat process inside sinter layer using finite volume method taking into account carbonates and hydrates dissociation. It is presented the plot of air speed and total amount of heat depending on the layer height.

In works [17, 18], the authors show details of agglomeration process including water phase transition, change in concentration of air and sinter components, coke combustion, sinter melting and crystallization. The authors present figures, which show the results of experiments.

Articles $[19,20]$ are devoted to the characteristics of gas circulation involved in sintering process. It is presented and compared temperature distributions for two technologies - FGRS and CS.

It is necessary to calculate the temperature distribution along the height and length of the layer, taking into account the change in the concentrations of the gas and the sinter layer during the physicochemical reactions of carbon burning, iron oxidation, decomposition of calcium carbonate, evaporation and condensation of water, melting and crystallization of the sinter.

\section{MATERIAL AND METHODS}

It is assumed that the layer retains the volume, and the sinter is a continuous medium. The geometry of a sinter layer, which has a length of about 30 meters and a height of 0.5 meters, allows us to use Cartesian system of coordinates (Fig. 1). The mathematical model includes a system of differential equations and additionally takes into account the influence of chemical reactions on the temperature distribution in the layer.

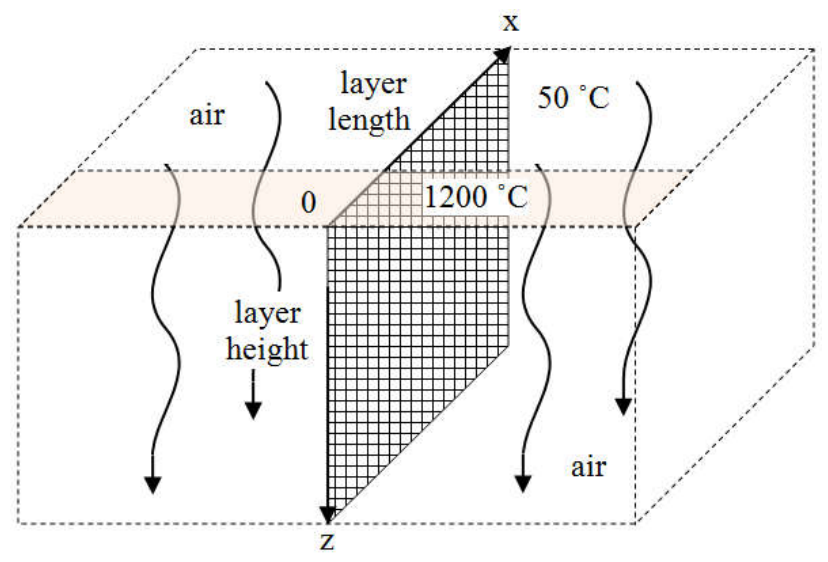

Figure 1 - Computational domain for the model

Below the equations are supplemented by the initial and boundary conditions.

The change in the oxygen concentration in the air, which vertically passes through the layer:

$$
\frac{\partial M_{\mathrm{O} 2}}{\partial t}+v_{z} \frac{\partial M_{\mathrm{O} 2}}{\partial z}=-m_{r \mathrm{O} 2} \text {. }
$$

The change in the $\mathrm{FeO}$ concentration in the layer:

$$
\frac{\partial M_{\mathrm{FeO}}}{\partial t}=-m_{\mathrm{rFeO}}
$$

The change in the carbon concentration in the layer:

$$
\frac{\partial M_{\mathrm{C}}}{\partial t}=-m_{\mathrm{rC}}
$$

The change in the water's vapor concentration in the air: 


$$
\frac{\partial M_{\mathrm{H} 2 \mathrm{Og}}}{\partial t}+v_{z} \frac{\partial M_{\mathrm{H} 2 \mathrm{Og}}}{\partial z}=m_{\mathrm{riH} 2 \mathrm{O}}-m_{\mathrm{rkH} 2 \mathrm{O}} \text {. }
$$
layer:

The change in the water concentration in the

$$
\frac{\partial M_{\mathrm{H} 2 \mathrm{O}}}{\partial t}=m_{\mathrm{rkH} 2 \mathrm{O}}-m_{\mathrm{riH} 2 \mathrm{O}} .
$$

The change in the $\mathrm{CaCO}_{3}$ concentration in the layer:

$$
\frac{\partial M_{\mathrm{CaCO} 3}}{\partial t}=-m_{\mathrm{rCaCO} 3}
$$

The change in the air temperature:

$$
\frac{\partial T_{\mathrm{gas}}}{\partial t}+v_{z} \frac{\partial T_{\mathrm{gas}}}{\partial z}=-Q_{\mathrm{tob}}
$$

It should be noted that equation (7) doesn't take into account $\mathrm{CO}$ oxidation, because of $\mathrm{CO}$ concentration isn't considered in the model. However, it can be included in the future as well as other chemical reactions, provided they play an important role in changing the gas temperature.

The change in the sinter temperature:

$$
\begin{gathered}
\frac{\partial T_{\mathrm{s}}}{\partial t}-a \Delta T_{\mathrm{s}}=Q_{\mathrm{tob}}+Q_{\mathrm{gC}}+Q_{\mathrm{gFeO}}- \\
-Q_{\mathrm{dCaCO} 3}-Q_{\mathrm{iH} 2 \mathrm{O}}+Q_{\mathrm{kH} 2 \mathrm{O}}-Q_{\mathrm{pl}}+Q_{\mathrm{kr}} .
\end{gathered}
$$

It is assumed a fully developed flow at the bottom of the layer, which is an outlet for air. It is a free passing flux through the outflow boundary $B$ :

$$
\left.\frac{\partial T_{\mathrm{gas}}}{\partial n}\right|_{B}=0,\left.\frac{\partial M_{\mathrm{O} 2}}{\partial n}\right|_{B}=0,\left.\frac{M_{\mathrm{H} 2 \mathrm{Og}}}{\partial n}\right|_{B}=0 .
$$

For the top of the layer boundary conditions depend on the state of the inlet air, which is heated by gas-burners only at the beginning of the layer and cooled at the defined part of the remaining top surface of the layer:

$$
\begin{gathered}
\left.T_{\text {gas }}\right|_{\text {top }}=\left\{\begin{array}{l}
1200, \text { if } d \leq 2 m \\
50, \quad \text { if } d>2 m
\end{array},\left.M_{\mathrm{O} 2}\right|_{\text {top }}=0.3\right. \\
M_{\left.\mathrm{H} 2 \mathrm{Og}\right|_{\text {top }}}=0.01 .
\end{gathered}
$$

In the equations above: $a$ - coefficient of thermal conductivity, $\mathrm{W} / \mathrm{m} / \mathrm{K} ; m_{\mathrm{rC}}-$ amount of reacted carbon, $\mathrm{kg} / \mathrm{m}^{3} / \mathrm{s} ; m_{\mathrm{rFeO}}$ - amount of reacted $\mathrm{FeO}$, $\mathrm{kg} / \mathrm{m}^{3} / \mathrm{s} ; m_{\mathrm{rO} 2}-$ amount of reacted oxygen, $\mathrm{kg} / \mathrm{m}^{3} / \mathrm{s}$;
$m_{\mathrm{riH} 2 \mathrm{O}}$ and $m_{\mathrm{rkH} 2 \mathrm{O}}$ - amount of evaporated and condensed water respectively, $\mathrm{kg} / \mathrm{m}^{3} / \mathrm{s} ; m_{\mathrm{rCaCO}}-$ amount of dissolved carbonate, $\mathrm{kg} / \mathrm{m}^{3} / \mathrm{s} ; Q_{\mathrm{tob}}-$ change in the temperature of the sinter due to heat transfer from the air to the sinter, $\mathrm{K} / \mathrm{s} ; Q_{\mathrm{gC}}$ and $Q_{\mathrm{gFeO}}$ - change in the temperature of the sinter from combustion of carbon and $\mathrm{FeO}$ respectively, $\mathrm{K} / \mathrm{s}$; $Q_{\mathrm{dCaCO} 3}$ - change in the sinter temperature from $\mathrm{CaCO}_{3}$ dissolution, $\mathrm{K} / \mathrm{s} ; \quad Q_{\mathrm{H} 2} \mathrm{O}$ and $Q_{\mathrm{kH} 2 \mathrm{O}}-$ contributions to the sinter temperature due to evaporation and condensation of water $\mathrm{K} / \mathrm{s} ; Q_{\mathrm{pl}}$ and $Q_{\mathrm{kr}}$ - contributions to the sinter temperature due to melting and crystallization of its components, $\mathrm{K} / \mathrm{s}$; $T_{\text {gas }}-$ air temperature, $\mathrm{K} ; T_{\mathrm{s}}-$ sinter temperature, $\mathrm{K}$; $v_{z}$ - vertical speed of air passing through sinter, which depends on its length, $\mathrm{m} / \mathrm{s} ; \mathrm{FeO}$ - iron oxide; $\mathrm{C}$ - carbon; $\mathrm{H}_{2} \mathrm{Og}$ - water vapor; $\mathrm{O}_{2}$ - oxygen; $\mathrm{CaCO}_{3}$ - calcium carbonate; $\mathrm{z}$ - axis from the top of the layer to its bottom.

The heat transfer between gas and solids is defined by Newton's law of cooling and the $Q_{\mathrm{tob}}$ is calculated using an empirical coefficient $h$ :

$$
Q_{\mathrm{tob}}=h\left(T_{\mathrm{gas}}-T_{\mathrm{s}}\right) .
$$

The equations above are solved using central difference numerical scheme with "minmod" flux limiter (to avoid nonphysical solution) for spatial derivatives and explicit Euler method for time derivatives. The calculation was done in the computer program Octave. The following initial data were used for the calculation: layer height $-0.5 \mathrm{~m}$; the length of the layer $-30 \mathrm{~m}$; the length of the preheating part $-5 \mathrm{~m}$; the average velocity of vertical gas flow through the layer is from 0.1 to 0.3 $\mathrm{m} / \mathrm{s}$, depending on the path traveled; the speed of the tape, which carries the layer is $2.9 \mathrm{~cm} / \mathrm{s}$; the initial temperature of the layer and gas is $30{ }^{\circ} \mathrm{C}$ (below the burners the gas temperature is $1200{ }^{\circ} \mathrm{C}$ ); the ignition temperature of the coke is $700{ }^{\circ} \mathrm{C}$; the number of steps for the computational grid along the length and height is 30 and 20 respectively; step by time - a quarter of the step along the height of the layer.

\section{RESULTS}

Figures (2-7) show the results of the numerical experiment. Designations in the figures are as follows: $\mathrm{Tg}-$ gas temperature; $\mathrm{Ts}$ - the temperature of the sinter; $\mathrm{T}\left(\mathrm{C}+\mathrm{O}_{2}\right)$ - coke ignition temperature; $\mathrm{O}_{2}$ - the oxygen in the air; $\mathrm{C}-$ carbon in the layer; $\mathrm{FeO}$ - iron oxide in the layer; $\mathrm{CaCO}_{3}-$ calcium carbonate in the layer; $\mathrm{H}_{2} \mathrm{O}$ - water in the layer (evaporates when it takes heat and condenses when heat is released in the lower layers of the sinter); $\mathrm{H}_{2} \mathrm{Og}$ - water in the air; the $\mathrm{x}$-axis is the height of the layer in centimeters, where 0 is the surface of the layer; $t$ and $d$ in the upper parts of the Figure - 
correspondingly time and distance traveled along the length by the sinter tape.

In Fig. 2, one can see the decrease in the oxygen concentration during the combustion of coke. It should be noted that in this paper a decrease in the rate of all physicochemical reactions in a linear dependence on the concentration of reagents is assumed.

Both Fig. 2 and Fig. 3 show the gradual accumulation of water in the lower layers of the sinter. This is because of the fact that in this process the air moving down the layer acts as a carrier of steam.

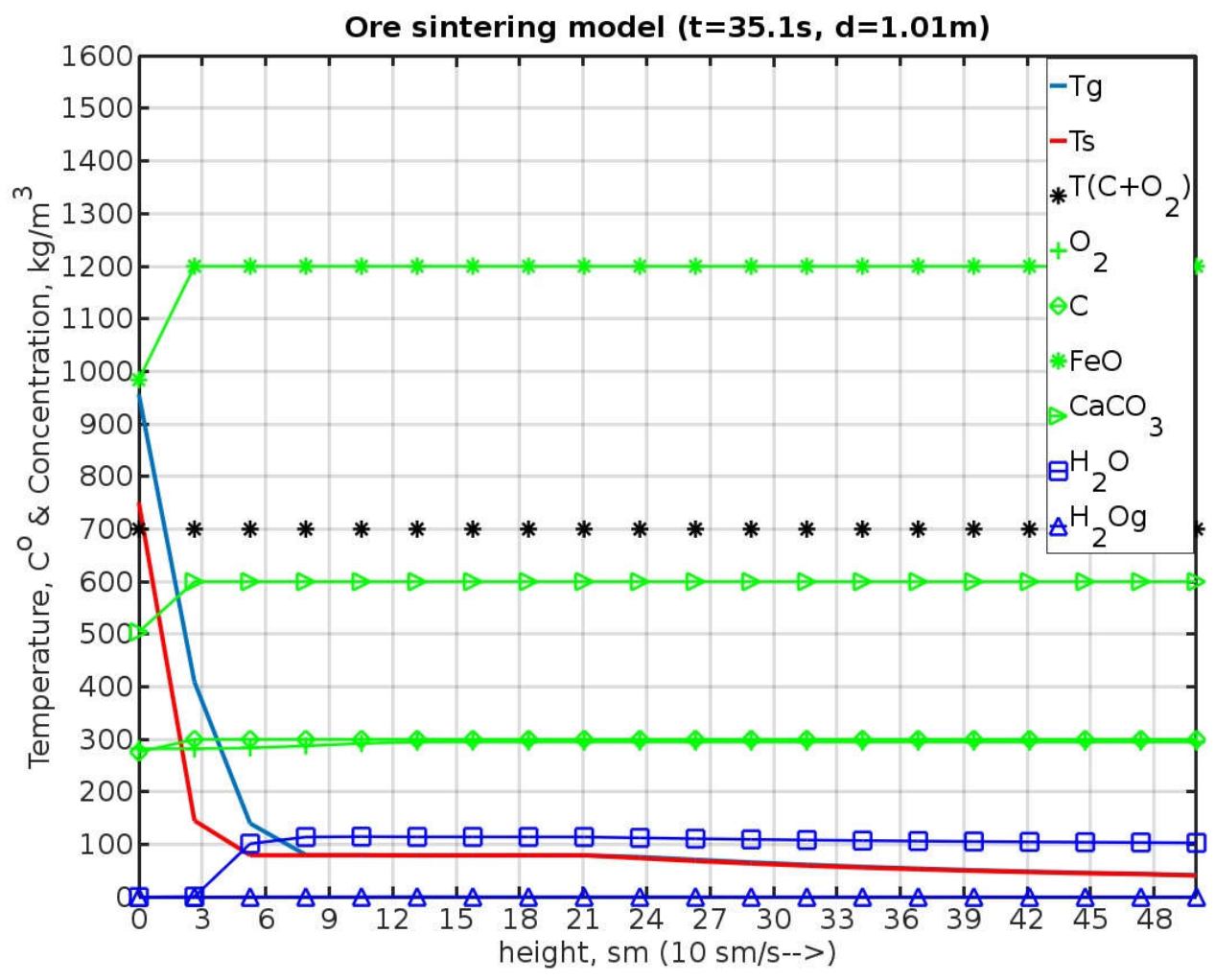

Figure 2 - The beginning of coke combustion reaction in the sinter $\left(\mathrm{T}>700{ }^{\circ} \mathrm{C}\right)$

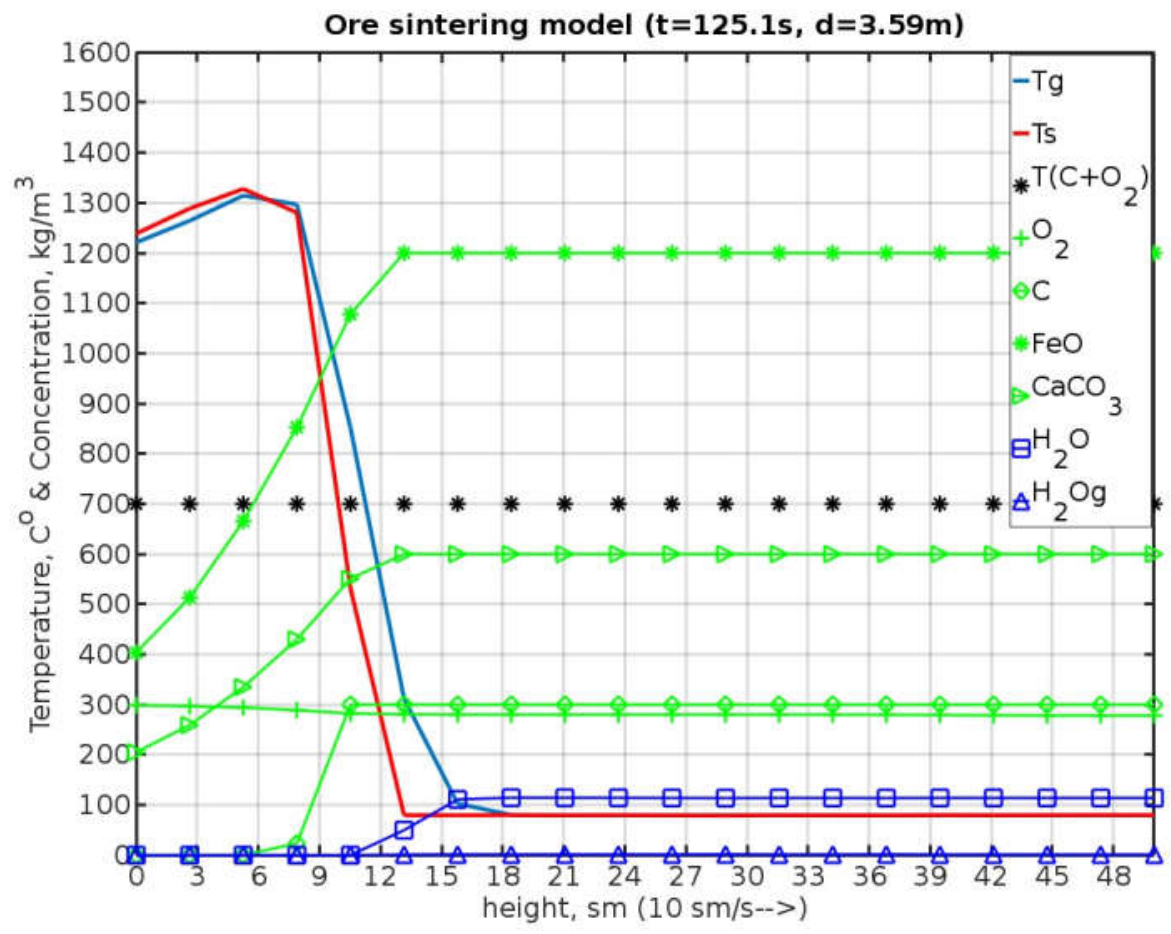

Figure 3 - An increase in temperature to $1300{ }^{\circ} \mathrm{C}$ in sinter when coke is burned out at a depth of $6 \mathrm{sm}$ 
In Fig. 4 the state of a layer's part is shown in the transition to the cooling region of the obtained agglomerate, where it is cooled by air with a temperature of about $50{ }^{\circ} \mathrm{C}$.

It can be seen in Figures 5-6, with increasing air speed from $0.2 \mathrm{~m} / \mathrm{s}$ to $0.3 \mathrm{~m} / \mathrm{s}$ through the layer, a more distinct difference between the temperature of the layer and the air temperature. Accordingly, the cooling rate of the layer also increases.

In Fig. 7, the external isolines correspond to low temperatures, and the internal ones correspond to temperature of about $1400{ }^{\circ} \mathrm{C}$. The area of coke ignition beneath the burners is clearly visible as well as the expansion of the high temperature region as the layer moves along the tape.

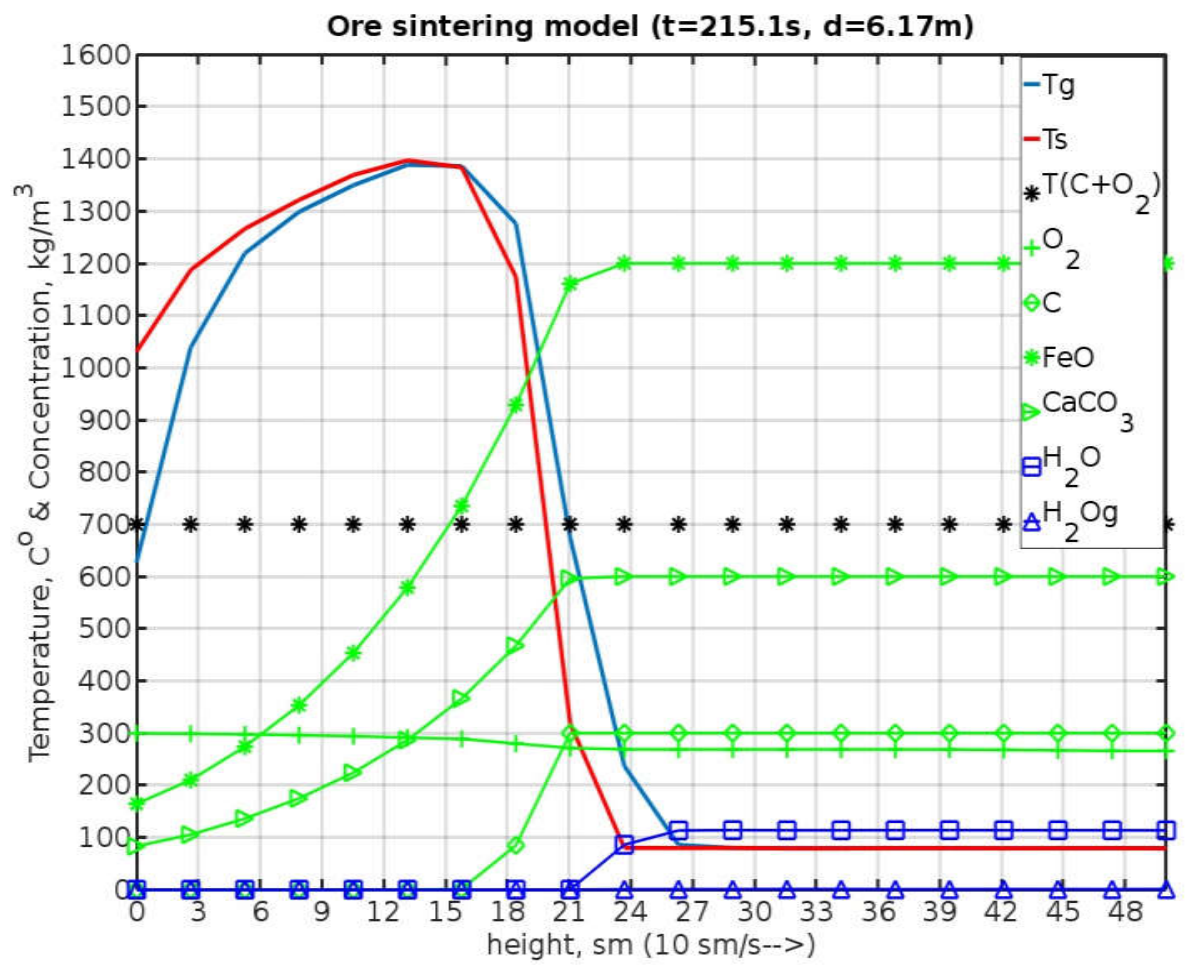

Figure 4 - Transition to cooling area

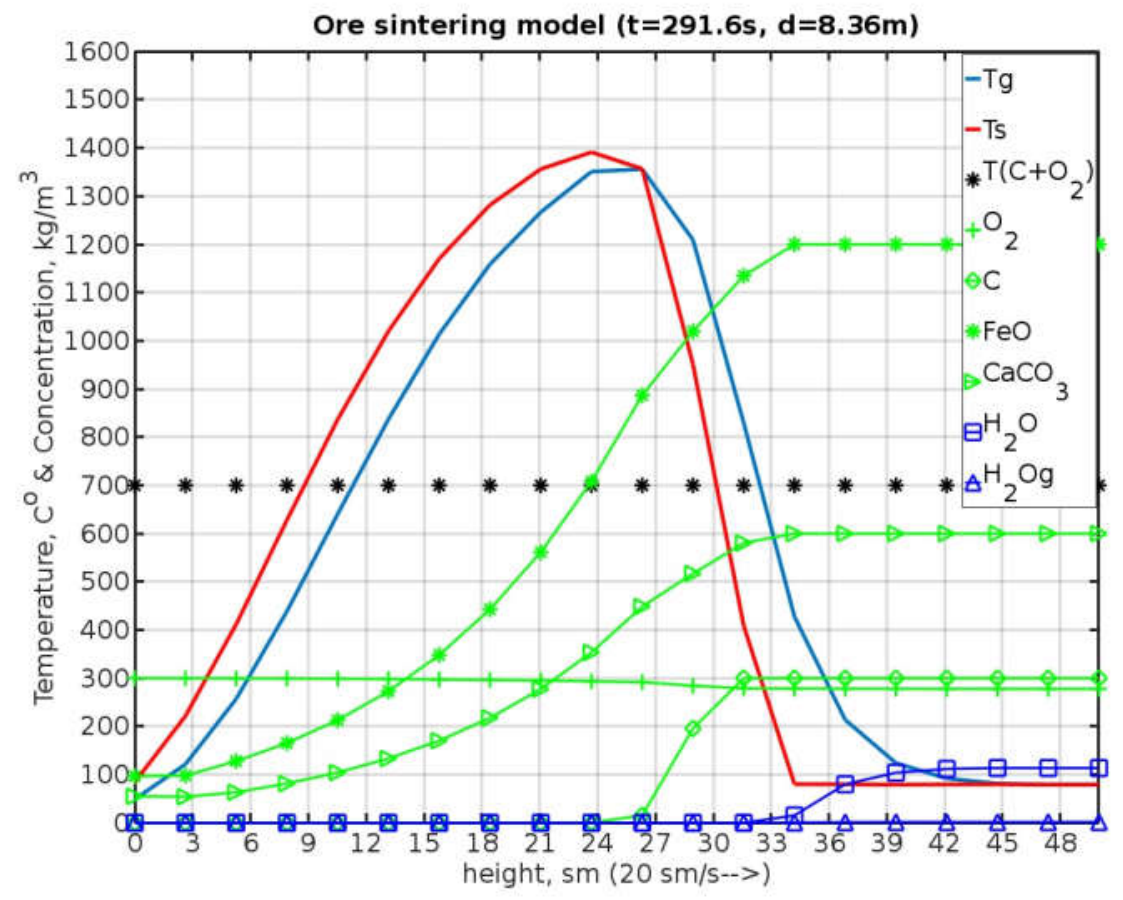

Figure 5 - An increase in speed of air passing through sinter to $0.2 \mathrm{~m} / \mathrm{s}$ 

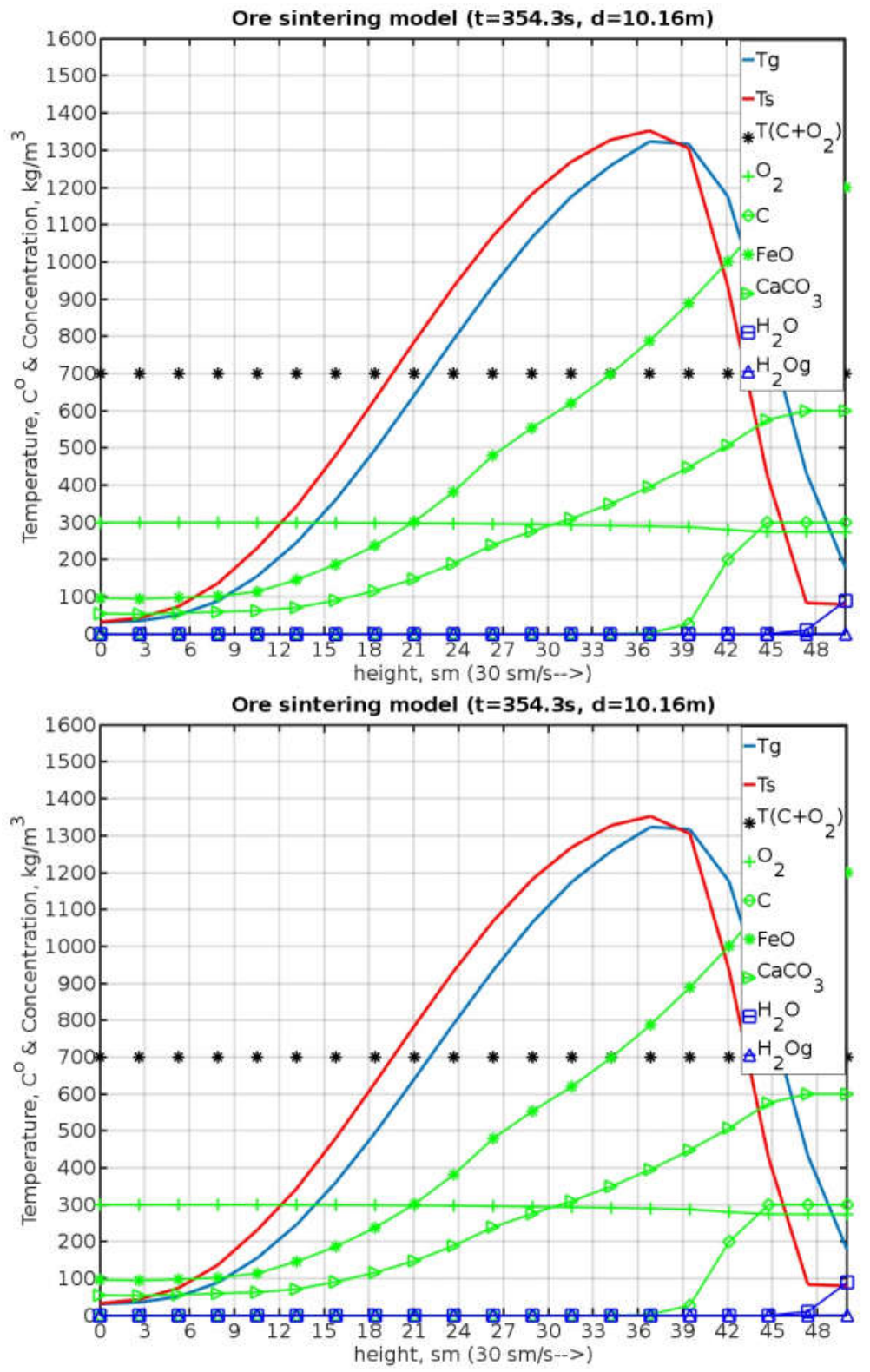

Figure 6 - An increase in air speed to $0.3 \mathrm{~m} / \mathrm{s}$ promotes further cooling

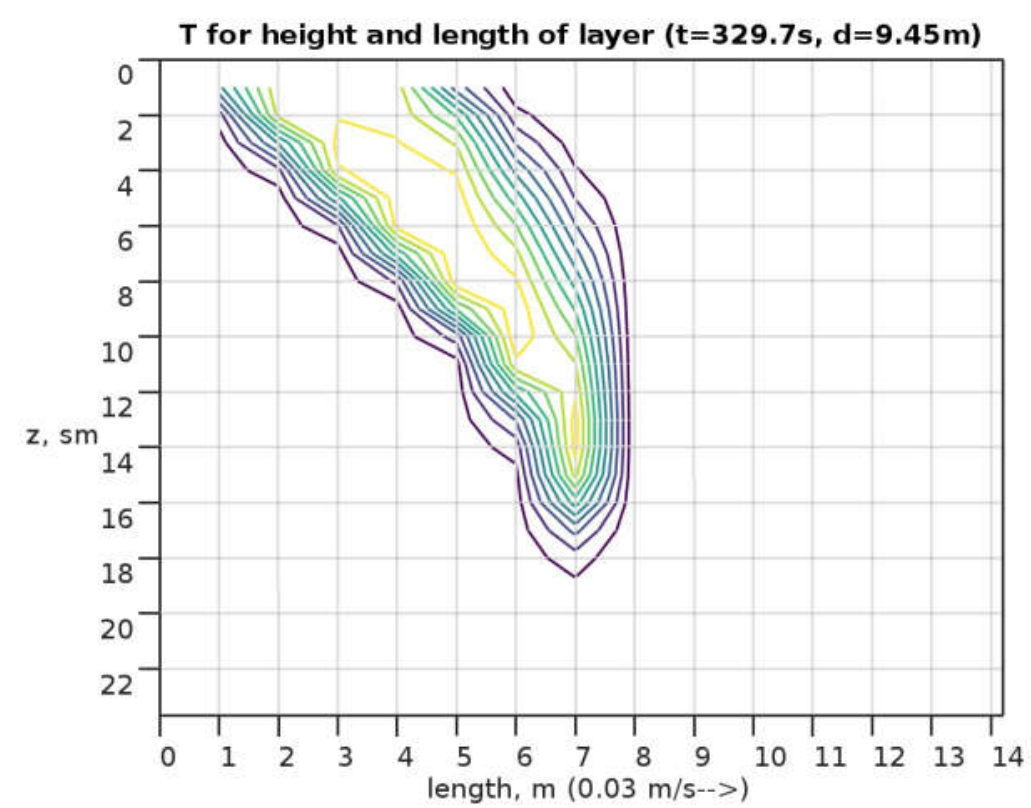

Figure 7 - Distribution of sinter temperature along the length and height of the layer 


\section{CONCLUSIONS}

In this work the temperature distribution in the layer is determined taking into account gas velocity and the change in the composition of the sinter due to physical and chemical reactions. If the Fig. 7 is compared to another one on page 365 of the work [17], then it can be stated that the obtained results are qualitatively consistent with the results of other researchers. However, quantitative adequacy needs to be verified.

In the future it is possible to take into account the heat losses from the walls of the pallets in which the sinter is located.

\section{ACKNOWLEDGEMENTS}

Author is grateful to the reviewers and to the professor M. I. Gasik for the idea of the paper.

\section{REFERENCES}

[1] Y. A. Frolov, L. I. Polotskii, "Threedimensional mathematical (dynamic) model of the sintering process. Part I," Metallurgist, vol. 58, issue 11-12, pp. 1071-1079, 2015.

[2] Y. A. Frolov, L. I. Polotskii, "Threedimensional mathematical (dynamic) model of the sintering process. Part II," Metallurgist, vol. 59, issue 1-2, pp. 9-15, 2015.

[3] D. R. Ganin, V. G. Druzhkov, A. A. Panychev, A. N. Shapovalov, "Review and analysis of mathematical models for calculating the performance of sintering machines," The Theory and Process Engineering of Metallurgical Production, vol. 15, Issue 2, pp. 20-25, 2014. (in Russian)

[4] A. A. Panychev, A. P. Nikonova, "Use of mathematical models to optimize process parameters in the sintering of Mikhailovskii and Lebedinskii concentrates," Metallurgist, vol. 52, issue 9-10, pp. 544-551, 2008.

[5] K. S. Krasnikov, S. P. Shuvaev, "Computer modeling of influence of sinter composition and average speed of air on temperature distribution in layer," in Proceedings of the International Conference on Information Technology in Metallurgy and Machine building, Dnipro, Ukraine, March 28-30, 2017, p. 39. (in Russian)

[6] J. A. de Castro, Modeling Sintering Process of Iron Ore, in: V. I. Shatokha (Ed.), Sintering Methods and Products, InTech, 2012, pp. 2346. ISBN: 978-953-51-0371-4, DOI: 10.13140/ RG.2.1.4666.7288.

[7] J. A. de Castro, Y. Sazaki, J. Yagi, "Three dimensional mathematical model of the iron ore sintering process based on multiphase theory," Materials Research, vol. 15, issue 6, pp. 848-858, 2012.

[8] V. I. Shatokha, O. G. Velychko, "Study of softening and melting behaviour of iron ore sinter and pellets," High Temperature Materials and Processes, vol. 31, pp. 215-220, 2012. DOI: 10.1515/htmp-2012-0027.

[9] S. Suman, B. K. Giri, G. G. Roy, "Mathematical modelling of iron ore sintering process using genetic algorithm: effect of moisture evaporation and condensation on the temperature profile," Computer Methods in Materials Science, vol. 1, pp. 141-146, 2013.

[10] J. Nalevankova, A. Varga, M. Kukurugyová, R. Dzurňák, "Heat transfer during the sintering process of iron ore," in Proceedings of Conference ISEC, July 20-24, 2015.

[11] J. Muller, T. L. de Vries, B. A. Dippenaar, J. C. Vreugdenburg, "A finite difference model of the iron ore sinter process," Journal of the Southern African Institute of Mining and Metallurgy, vol. 115, issue 5, pp. 409-417, 2015.

[12] J. Muller, Journal of the Southern African Institute of Mining and Metallurgy, [Online]. Available: http://www.saimm.co.za/Conferen ces/PyroModelling/061-Muller.pdf.

[13] R. Straka, T. Telejk, "1D mathematical model of coke combustion," International Journal of Applied Mathematics, vol. 45, issue 3, pp. 245248, 2015.

[14] E. G. Egorova, Operational control of the process of iron ore sinter production, $\mathrm{PhD}$ Thesis, St. Petersburg State Technological Institute (technical university), 2016, 133 p. (in Russian)

[15] A. S. Mnyh, "The study of the amount of heat release in the sinter charge layer," EasternEuropean Journal of Enterprise Technologies, vol. 6, issue 5, pp. 14-18, 2014. (in Ukrainian)

[16] A.S. Mnyh, The improving of energy efficiency of thermal processes of bulk materials clotting with segregation intensification in stationary layers, DSc Thesis, Odessa National Polytechnic University, 2016, 355 p.

[17] V. I. Korotich, Yu. A. Frolov, G. N. Bezdezhskii, Agglomeration of Ore-Bearing Materials, UGTU-UPI (Ural State Technical University Ural Polytechnic Institute), Ekaterinburg, 2003, 400 p. (in Russian). ISBN 5-321-00336-X.

[18] A.A. Eliseev, Research of Heat and Mass Transfer Processes during Sinter Agglomeration, Cherepovets State University, 2006, 24 p. (in Russian)

[19] G. Wang, Z. Wen, G. Lou, R. Dou, X. Li, X. Liu, F.Su, "Mathematical modeling and combustion characteristic evaluation of a flue 
gas recirculation iron ore sintering process," International Journal of Heat and Mass Transfer, Vol.97, pp 964-974, 2016. DOI: 10.1016/j.ijheatmasstransfer.2016.02.087.

[20] X.-H. Fan, Z.-Y. Yu, M. Gan, W.-Q. Li, Z. Ji, "Influence of $\mathrm{O} 2$ Content in Circulating Flue Gas on Iron Ore Sintering," Journal of Iron and Steel Research International, Vol. 20, Issue 6, pp. 1-6, 2013. DOI: 10.1016/S1006-706X(13) 60103-X.

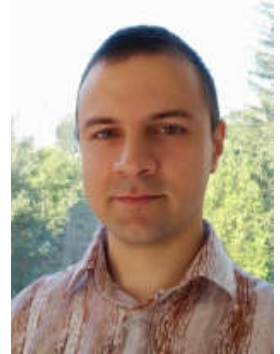

Kyrylo S. Krasnikov in 2009 graduated from Dniprovsky State Technical University with M.S. in Software Engineering; at the end of 2016 was awarded a PhD by National metallurgical academy of Ukraine in Mathematical simulation and methods of calculation. Now

he is a senior lecturer at DSTU.

Scientific interests: CFD, dynamics of solids, thermo-dynamics; C++, C\#, Java app development. 